\title{
Copy number analysis of 413 isolated talipes equinovarus patients suggests role for transcriptional regulators of early limb development
}

\author{
David M Alvarado ${ }^{1}$, Jillian G Buchan ${ }^{2}$, Steven L Frick ${ }^{3}$, John E Herzenberg ${ }^{4}$, Matthew B Dobbs ${ }^{1,5}$ and \\ Christina A Gurnett ${ }^{*, 1,6,7}$
}

Talipes equinovarus is one of the most common congenital musculoskeletal anomalies and has a worldwide incidence of 1 in 1000 births. A genetic predisposition to talipes equinovarus is evidenced by the high concordance rate in twin studies and the increased risk to first-degree relatives. Despite the frequency of isolated talipes equinovarus and the strong evidence of a genetic basis for the disorder, few causative genes have been identified. To identify rare and/or recurrent copy number variants, we performed a genome-wide screen for deletions and duplications in 413 isolated talipes equinovarus patients using the Affymetrix 6.0 array. Segregation analysis within families and gene expression in mouse E12.5 limb buds were used to determine the significance of copy number variants. We identified 74 rare, gene-containing copy number variants that were present in talipes equinovarus probands and not present in 759 controls or in the Database of Genomic Variants. The overall frequency of copy number variants was similar between talipes equinovarus patients compared with controls. Twelve rare copy number variants segregate with talipes equinovarus in multiplex pedigrees, and contain the developmentally expressed transcription factors and transcriptional regulators PITX1, TBX4, HOXC13, UTX, CHD (chromodomain protein) 1, and RIPPLY2. Although our results do not support a major role for recurrent copy number variations in the etiology of isolated talipes equinovarus, they do suggest a role for genes involved in early embryonic patterning in some families that can now be tested with large-scale sequencing methods.

European Journal of Human Genetics (2013) 21, 373-380; doi:10.1038/ejhg.2012.177; published online 15 August 2012

Keywords: talipes equinovarus; microduplication; microdeletion; transcription

\section{INTRODUCTION}

Isolated talipes equinovarus, also called clubfoot, is one of the most common serious congenital birth defects with an estimated birth prevalence of 1 per 1000 live births. ${ }^{1}$ Talipes equinovarus consists of malalignment of the bones and joints of the foot and ankle, and is distinguished from positional foot anomalies because it is rigid and not passively correctable (Figure 1). Approximately 20\% of talipes equinovarus cases are associated with chromosomal abnormalities, or known genetic syndromes ${ }^{2,3}$ and it is a common component of several neurological disorders, including distal arthrogryposis, myotonic dystrophy, and myelomeningocele. Despite the frequency of talipes equinovarus in neurological disorders, no consistent neuromuscular abnormalities have been identified in isolated talipes equinovarus patients using muscle biopsy or electrophysiological examinations. $^{4-7}$ Most cases of clubfeet $(80 \%)$ occur as isolated birth defects and are considered idiopathic. ${ }^{8}$

Approximately $25 \%$ of patients with isolated talipes equinovarus report a family history of talipes equinovarus, suggesting a genetic basis for this disorder. ${ }^{9}$ Twin studies also support a role for genetic factors, as identical twins have a $33 \%$ concordance rate for talipes equinovarus compared with a $3-4 \%$ concordance rate in fraternal twins. ${ }^{8}$ Familial isolated talipes equinovarus follows a complex inheritance pattern in most families and is not typically inherited in a simple Mendelian pattern. In New Zealand Polynesian populations with a high incidence of talipes equinovarus, the best model of inheritance is autosomal dominant with a low penetrance $(33 \%) .{ }^{10} \mathrm{In}$ other populations, regressive logistic models of complex segregation suggest a single major gene effect with autosomal recessive, ${ }^{11}$ or autosomal dominant inheritance ${ }^{12}$ and an additional effect (polygenetic or environmental factors) shared among siblings. ${ }^{13}$

The genetic basis of talipes equinovarus is gradually being revealed. Candidate gene studies of common polymorphisms near HOX homeobox genes, insulin-like growth factor binding protein $3^{14}$ and caspase genes ${ }^{15}$ are associated with isolated talipes equinovarus, although they likely explain only a small amount of the variance in talipes equinovarus susceptibility. Rare mutations have been identified in genes involved in early limb development, including our previous identification of a single missense mutation in the bicoid-related homeodomain transcription factor gene (PITX1) in a multigenerational family with isolated talipes equinovarus. ${ }^{16}$

${ }^{1}$ Department of Orthopaedic Surgery, Washington University School of Medicine, St Louis, MO, USA; ${ }^{2}$ Division of Biology and Biomedical Sciences, Washington University School of Medicine, St Louis, MO, USA; ${ }^{3}$ Levine Children's Hospital, Charlotte, NC, USA; ${ }^{4}$ Sinai Hospital, Baltimore, MD, USA; ${ }^{5}$ t Louis Shriners Hospital for Children, St Louis, MO, USA; ${ }^{6}$ Department of Pediatrics, Washington University School of Medicine, St Louis, MO, USA; ${ }^{7}$ Department of Neurology, Washington University School of Medicine, St Louis, MO, USA

${ }^{*}$ Correspondence: Professor CA Gurnett, Department of Neurology, Pediatrics, and Orthopaedic Surgery, 660 South Euclid Avenue, St Louis, MO 63110, USA. Tel: +1 (314) 286 2789; Fax: +1 (314) 286 2894. E-mail: gurnettc@neuro.wustl.edu

Received 29 December 2011; revised 10 July 2012; accepted 10 July 2012; published online 15 August 2012 
PITX1 $^{+/-}$mice also exhibit abnormalities in hindlimb growth, ${ }^{17}$ including a low penetrant, often unilateral talipes equinovarus-like phenotype similar to humans. ${ }^{18}$ Despite these findings, however, the genes responsible for most cases of talipes equinovarus remain unknown.

Copy number variation (CNV) analysis has frequently been used to identify potential causative genes for neuropsychiatric disorders and disorders associated with multiple congenital abnormalities (reviewed in Cook and Scherer ${ }^{19}$; Morrow ${ }^{20}$; Stankiewicz and Lupski ${ }^{21}$ ). However, few studies have used $\mathrm{CNV}$ analysis to study isolated human birth defects. ${ }^{18,22-25}$ Rare CNVs may serve to identify candidate genes that are more typically altered by other mechanisms (ie point mutations) or they may delineate a microdeletion syndrome. Alternatively, common CNVs may be significantly more frequent in a patient population, exerting only small to modest effects on disease susceptibility.

We previously reported a CNV screen of 40 familial isolated talipes equinovarus probands and identified a chromosome $5 \mathrm{q} 31$ microdeletion involving PITX1 ${ }^{18}$ and recurrent chromosome 17q23 copy number variants involving the T-box transcription factor TBX4 in familial talipes equinovarus probands. ${ }^{22}$ TBX4 is a known transcriptional target of $P I T X 1^{26,27}$ and is required for normal hindlimb development, ${ }^{28-31}$ further supporting a role for the PITX1-TBX4 developmental pathway in talipes equinovarus etiology. Furthermore, PITX1 and TBX4 are two genes that are specifically expressed in the hindlimb compared with the forelimb, providing an explanation for the selective limb phenotype.

Here, we report rare and recurrent $\mathrm{CNV}$ s associated with isolated talipes equinovarus in a large series of 413 patients. To determine the significance of these CNVs, we performed segregation analysis in large talipes equinovarus pedigrees, as well as gene expression analysis in mouse E12.5 limb buds. Novel talipes equinovarus candidate genes disrupted by these CNVs suggest the importance of genes involved in transcriptional regulation of early limb development and provide important insights into the pathways responsible for this common human birth defect.

\section{MATERIALS AND METHODS}

\section{Patient samples}

We identified 420 isolated idiopathic talipes equinovarus probands from the Washington University Musculoskeletal DNA Databank who were recruited from St Louis Children's Hospital, St Louis Shriners Hospital, Levine Children's Hospital (Charlotte), or Sinai Hospital (Baltimore). The study protocol was approved by the Institutional Review Board of each institution, and all subjects and/or parents gave informed consent. Patients were diagnosed with talipes equinovarus based on the physical examination findings by a single orthopedic surgeon from each contributing institution. Individuals were excluded if they had additional congenital anomalies, developmental delay, or known underlying etiologies such as arthrogryposis, myelomeningocele, or myopathy. Blood and saliva samples were collected from affected individuals and unaffected, and affected family members when available. DNA extractions were performed using the manufacturer's protocols using either the DNA Isolation Kit for Mammalian Blood (Roche, Indianapolis, IN, USA) or the Oragene Purifier for saliva (DNA Genotek, Kanata, ON, Canada).

\section{CNV data analysis}

Isolated talipes equinovarus probands were screened for genomic copy number variants (CNVs) on the Genome-wide Human SNP Array 6.0 (Affymetrix, Santa Clara, CA, USA). Copy number polymorphisms were called using the Affymetrix Genotype Console, Birdsuite software (Affymetrix) and copy number intensities for each marker were evaluated against 270 HapMap reference samples. Samples with contrast $\mathrm{QC}<0.4$ and MAPD $>0.35$ were

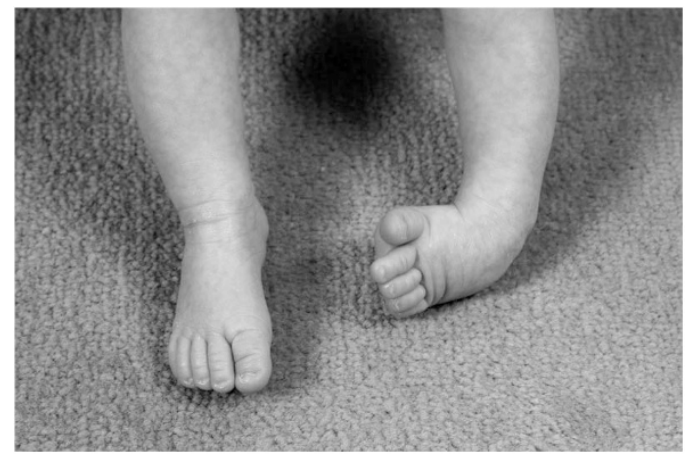

Figure 1 Photograph of patient with unilateral, left-sided isolated talipes equinovarus.

excluded from further analysis $(n=7)$, thus 413 probands were used to identify novel CNVs. CNVs were quantitatively limited to those $\geq 125 \mathrm{~kb}$ in size and $\geq 50$ markers with $<50 \%$ overlap with known CNVs attained from the Database of Genomic Variants (DGV) (http://projects.tcag.ca/variation) and 666 Caucasian controls of European-American ancestry from a bipolar disorder study ${ }^{32,33}$ and 93 scoliosis Caucasian controls (unpublished data) evaluated with the same platform (Affymetrix 6.0). Copy number changes were also visually inspected in the Affymetrix Genome Browser. A subset of CNVs, including all of the CNVs described in Table 1, were validated by quantitative PCR using three PCR primers per CNV and segregation analysis was performed using the indicated family members.

\section{Gene expression profiling}

Hindlimb buds were collected from wild-type mice at embryonic day E12.5. Hindlimb buds from two embryos (four hindlimb buds) were combined for each biological sample. Total RNA was extracted using Trizol (Invitrogen, Carlsbad, CA, USA) and further purified using RNeasy (Qiagen, Venlo, Netherlands). Three biological samples were hybridized to the MouseRef8expression Bead Chip (Illumina, San Diego, CA, USA), performed by the Washington University Microarray Core Facility and analyzed with Bead Studio (Illumina) software. Expression values were quantile normalized and detection $P$-values were determined for each probe. Mean signal intensities were calculated for present probes using the manufactures recommended threshold, defined as detection $P$-values $<0.05^{34}$ across three biological replicates.

\section{RESULTS}

To determine whether genomic copy number variants (CNVs) are responsible for isolated talipes equinovarus, 413 Caucasian probands were screened for CNVs with the Affymetrix Genome-wide Human SNP Array 6.0. The cohort was typical of isolated talipes equinovarus and consisted of $16 \%$ familial (defined as having a first-degree relative affected with isolated talipes equinovarus), 66\% male, and $61 \%$ bilateral talipes equinovarus patients (Table 2). We limited our analysis to CNVs that were $\geq 125 \mathrm{~kb}$ and supported by $\geq 50$ markers in order to enrich our data set for high confidence variants because all tested CNVs meeting these criteria were confirmed with rt-PCR $(n=20)$.

\section{Rare CNVs identified in talipes equinovarus probands}

To identify rare variants, we considered only CNVs with $<50 \%$ overlap with known CNVs obtained from the DGV and 759 controls evaluated with the same Affymetrix 6.0 platform. We identified $118 \mathrm{CNVs}$ in 94 talipes equinovarus probands that were not present in unrelated Caucasian controls of European-American ancestry (Table 3). (See Supplementary Table 1 for a list of all rare $\mathrm{CNVs}$ ). These rare $\mathrm{CNV}$ s range in size from $125 \mathrm{~kb}$ to $3.6 \mathrm{Mb}$ 
Table 1 Segregation analysis of rare CNVs identified in isolated talipes equinovarus probands and validated by qPCR

\begin{tabular}{|c|c|c|c|c|c|c|c|}
\hline Sample & CNV & Position (Hg18) & Size $(k b)$ & Markers & Segregation & Genes & Candidate genes (haploinsufficiency index ${ }^{35}$ \\
\hline \multicolumn{8}{|c|}{ Segregating or de novo CNVs } \\
\hline 5143001 & Gain & chr1:14676972-14857242 & 180 & 148 & Yes & 1 & KAZRIN \\
\hline 5480001 & Loss & chr5:97916544-98250268 & 334 & 201 & De novo & 4 & CHD1 (5.4\%), RGMB (61.2\%) \\
\hline 5437001 & Loss & chr5:134222383-134463022 & 241 & 124 & Yes & 9 & PITX1 (11.0\%), TXNDC15 (73.2\%), PCBD2 (62.7\%) \\
\hline 5173001 & Gain & chr6:84554589-85163713 & 448 & 287 & Yes & 2 & CYB5R4 (46.9\%), RIPPLY2a \\
\hline 5770001 & Loss & chr10:87438277-88020530 & 582 & 434 & Yes & 2 & $\operatorname{GRID1}(26.5 \%)^{\mathrm{a}}$ \\
\hline 5106001 & Loss & chr11:84267047-84396920 & 130 & 110 & Yes & 1 & DLG2 (0.9\%) \\
\hline 5575001 & Loss & chr12:52451268-52621935 & 171 & 126 & Yes & 1 & HOXC13 (24.4\%) \\
\hline 5103001 & Gain & chr17:55457520-57693617 & 2236 & 1120 & Yes & 20 & $\begin{array}{c}\text { TBX4 (5.4\%), TBX2 (9.4\%), BRIP1 (44.4\%), } \\
\text { APPBP2 (7.6\%), BCAS3 (12.6\%), PPM1D (12.4\%) }\end{array}$ \\
\hline 5377001 & Gain & chr17:55457520-57680004 & 2222 & 1119 & Yes & 20 & $\begin{array}{c}\text { TBX4 (5.4\%), TBX2 (9.4\%), BRIP1 (44.4\%), } \\
\text { APPBP2 (7.6\%), BCAS3 (12.6\%), PPM1D (12.4\%) }\end{array}$ \\
\hline 5077001 & Loss & chr20:59467898-59716357 & 248 & 170 & Yes & 1 & $\mathrm{CDH} 4(66.3 \%)$ \\
\hline 5055001 & Gain & chrX:42843862-44140849 & 1297 & 760 & Yes & 6 & MAOB (17.7\%) \\
\hline 5788001 & Gain & chrX:44701543-44916552 & 215 & 96 & Yes & 2 & UTX (1.1\%) \\
\hline \multicolumn{8}{|c|}{ Indeterminate CNVs } \\
\hline 5254001 & Gain & chr2:48615046-49323776 & 709 & 527 & In unaffected mother & 6 & STON1, GTF2AIL, LHCGR (66.3\%), FSHR (86.2\%) \\
\hline 5474001 & Gain & chr6:118749378-119208433 & 459 & 279 & In mother with flat feet & 2 & C6orf204 (38.6\%), PLN (12.6\%) \\
\hline 5712001 & Loss & chr11:126236865-129305894 & 3069 & 2372 & In unaffected father & 25 & ETS1 (12.1\%), NFRKB (46.3\%), FLI1 (13.2\%) \\
\hline 5772001 & Loss & chr12:86004128-89609221 & 3605 & 2109 & In unaffected mother & 15 & DUSP6 (27.5\%), WDR51B (56.2\%), ATP2B1 (3.0\%) \\
\hline \multicolumn{8}{|c|}{ Non-segregating CNVs } \\
\hline 5494001 & Loss & chr6:15338231-15471363 & 133 & 65 & No & 2 & JARID2 (1.4\%) \\
\hline 5245001 & Loss & chr13:97642475-97925497 & 283 & 273 & No & 3 & STK24 (12.2\%) \\
\hline 5274001 & Gain & chr19:58615732-59108796 & 493 & 331 & No & 18 & CACNG7 (37.9\%), MYADM (72\%) \\
\hline
\end{tabular}

Abbreviations: CNV, copy number variation; qPCR, quantitative.

Bold indicates genes expressed in E12.5 mouse hindlimb.

aNot represented on array from which expression data was derived.

Table 2 Demographics of 420 isolated talipes equinovarus probands studied with CNV analysis

\begin{tabular}{lccc}
\hline & Familial & Non-familial & Total \\
\hline Total & $66(16 \%)$ & $354(84 \%)$ & 420 \\
Male & $44(16 \%)$ & $234(84 \%)$ & $278 / 420(66 \%)$ \\
Female & $22(15 \%)$ & $120(85 \%)$ & $142 / 420(34 \%)$ \\
Right-sided & $9(11 \%)$ & $72(89 \%)$ & $81 / 420(19 \%)$ \\
Left-sided & $10(12 \%)$ & $72(88 \%)$ & $82 / 420(20 \%)$ \\
Bilateral & $47(18 \%)$ & $210(82 \%)$ & $257 / 420(61 \%)$ \\
\hline
\end{tabular}

Abbreviation: CNV, copy number variation.

(average $=415.1 \mathrm{~kb}$, median $=225 \mathrm{~kb}$ ), and consist of 41 deletions and 77 duplications. There was no difference in the number of individuals with large CNVs, $(>500 \mathrm{~kb})$ in cases $(16 / 413,3.87 \%)$ compared with controls $(32 / 759,4.38 \%)$.

Candidate genes disrupted by rare CNVs

To identify potential candidate genes associated with talipes equinovarus, we evaluated only CNVs that overlap one or more UCSC (University of California Santa Cruz) genes. With this approach, we identified $74 \mathrm{CNV}$ s in 61 talipes equinovarus probands whose genome contains $\geq$ one rare gene-containing deletion or duplication. Of these, 23 CNVs involve a single gene and 51 involve multiple genes. We then determined which of these genes are expressed in the developing hindlimb at a relevant developmental time period by performing expression analysis of mouse E12.5 hindlimb buds using the Illumina
Table 3 Summary of rare CNVs identified in 413 isolated talipes equinovarus probands

\begin{tabular}{lc}
\hline Isolated talipes equinovarus samples & 413 \\
Samples with rare CNVs & 94 \\
Total rare CNVs & 118 \\
Rare CNVs containing UCSC genes & 74 \\
Average CNV size & $415.1 \mathrm{~kb}$ \\
Median CNV size & $225 \mathrm{~kb}$ \\
Duplications & 77 \\
Deletions & 41 \\
Large CNVs (>500 kb) & 16 \\
Percent cases with large CNVs & $3.87 \%$ \\
Percent controls with large CNVs & $4.38 \%$
\end{tabular}

Abbreviation: CNV, copy number variation.

MouseRef-8 expression Bead Chip. This strategy was chosen as several genes previously shown to be associated with talipes equinovarus are expressed at this time in limb development. ${ }^{18,22}$ In the CNVs that were identified in our isolated talipes equinovarus patient cohort, we identified 74 genes that are expressed at E12.5 in the developing mouse hindlimb (Supplementary Table 2).

Segregation analysis of rare CNVs in talipes equinovarus families To determine the pathologic significance of the identified CNVs, we selected $20 \mathrm{CNVs}$ to test for segregation within families (Table 1). We prioritized large CNVs ( $>500 \mathrm{~kb}$ ), and CNVs containing UCSC genes that are expressed in the E12.5 mouse hindlimb or are known to be involved in limb development. We identified $11 \mathrm{CNV}$ s that segregate 


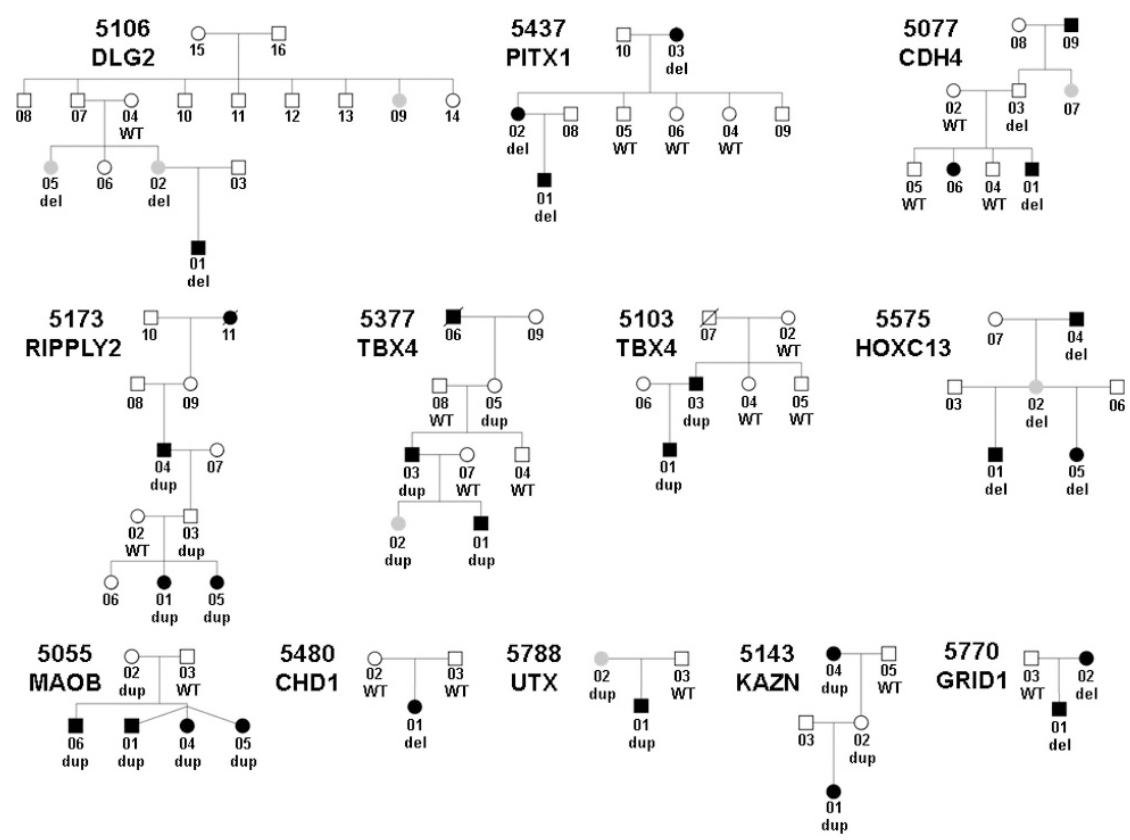

Figure 2 Pedigrees showing segregation of CNVs with isolated talipes equinovarus. The gene listed below the family number is considered the most likely causative gene within the CNV, although the CNV may contain several genes. Black affection status indicates isolated talipes equinovarus and gray indicates the following: 5106, intoeing requiring orthotics; 5077, hip dysplasia; 5377, hip dysplasia; 5575, hammertoes; 5788, early-onset arthritis. Dup indicates duplication, del indicates deletion, and WT indicates normal copy number. More details about these CNVs are listed in Table 3.

with talipes equinovarus and one de novo $\mathrm{CNV}$ (Figures 2 and 3 ). These include two families with identical $2.1 \mathrm{Mb}$ recurrent chromosome 17q23 duplications involving TBX4 that we described previously $^{22}$ and a deletion of PITX1 segregating over three generations that was also described previously. ${ }^{18}$ We identified four CNVs that segregated with talipes equinovarus with reduced penetrance and three CNVs that were validated in the affected probands, but failed to segregate with all affected family members.

\section{Clinically relevant recurrent CNVs identified in talipes equinovarus patients}

In addition to studying novel rare CNVs associated with isolated talipes equinovarus, we also identified common recurrent CNVs that are present in the DGV and may be clinically relevant to the talipes equinovarus phenotype (Table 4). Deletions and duplications of chromosome $2 \mathrm{q} 13$ have been previously described in patients with hypotonia, developmental delay, limb contractures, and cranial dysmorphic features. ${ }^{36,37}$ We identified a de novo deletion of chromosome $2 \mathrm{q} 13$ in one talipes equinovarus patient and none of our controls. Although this patient was developmentally normal at the time of the study (age 1), by the time of publication (age 3) she was noted to have mild motor delay.

Large recurrent 10q22q23 deletions and duplications overlapping >30 UCSC genes (at hg18: chr10:81682644-88931994) have previously been described in patients with cognitive and neurobehavioral abnormalities, and dysmorphic features. ${ }^{41,42}$ Hypotonia was described in three patients and a single patient had bilateral talipes equinovarus. We identified a $582 \mathrm{~kb}$ microdeletion (chr10:87438277-88020530) within this region resulting in the deletion of a single gene, the glutamate receptor, ionotropic, delta 1 (GRID1), in an affected mother and son, suggesting a possible role for GRID1 in the etiology of talipes equinovarus.
Deletions and duplications of chromosome 16p13.1 have been implicated in a variety of neuropsychiatric disorders, ${ }^{38}$ thoracic aortic aneurysms and dissection, ${ }^{39}$ as well as skeletal manifestations including hypermobility, craniosynostosis, and polydactyly. ${ }^{40}$ We identified an enrichment of chromosome 16p13.1 CNVs $(P=0.036)$, consisting of one deletion and three duplications in our isolated talipes equinovarus cohort and a single duplication in our bipolar controls. These patients are all developmentally normal and lack family history of aortic or neuropsychiatric disease.

We also identified two small CNVs in talipes equinovarus patients consisting of either a partial deletion or duplication of the larger chromosome 22q11.2 region that causes DiGeorge syndrome. ${ }^{43,44}$ DiGeorge syndrome presents with a variety of manifestations including palatal anomalies, velopharyngeal insufficiency, heart defects, hypocalcemia, immune deficiency, and facial anomalies. Although skeletal anomalies are not a defining feature of DiGeorge syndrome, rare cases of lower limb defects including talipes equinovarus have been described in chromosome 22q11 deletions. $^{45-47}$

Finally, we detected two individuals with Klinefelter's syndrome (XXY) who were not previously known to have this disorder. Like the other individuals in this study, these individuals presented with isolated talipes equinovarus, and are cognitively and physically normal at $>5$ years follow-up.

\section{DISCUSSION}

Genomic copy number analysis is a powerful method for providing insight into disease pathogenesis. Although its predominant use has been in studying individuals with neuropsychiatric disorders or multiple congenital anomalies, our research adds to the literature supporting the use of $\mathrm{CNV}$ analysis to study isolated birth defects. ${ }^{23-25,48}$ Copy number analysis can be particularly effective for parsing out genetic pathways when, as in our case, it can be used 

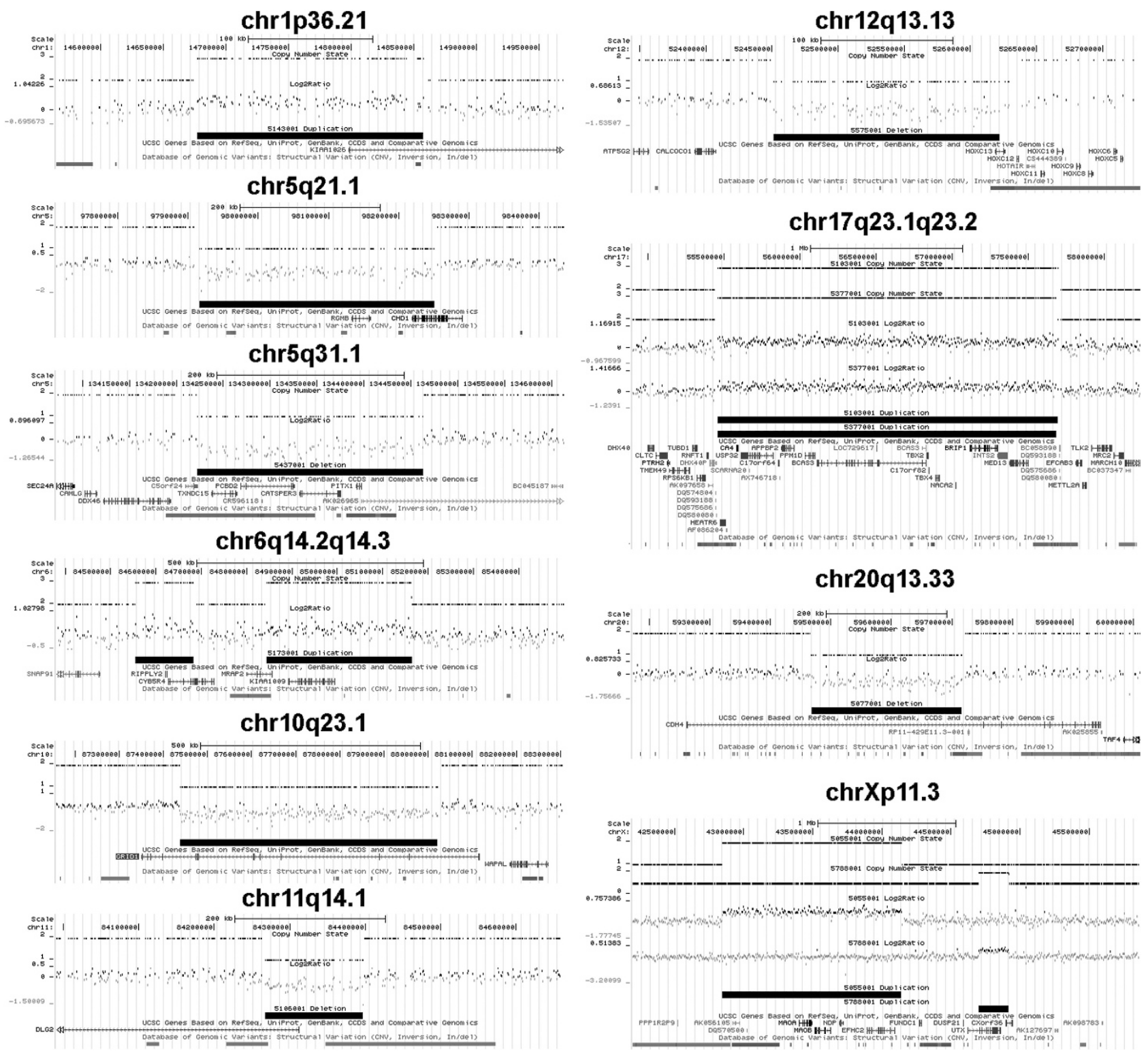

\section{chr20q13.33}

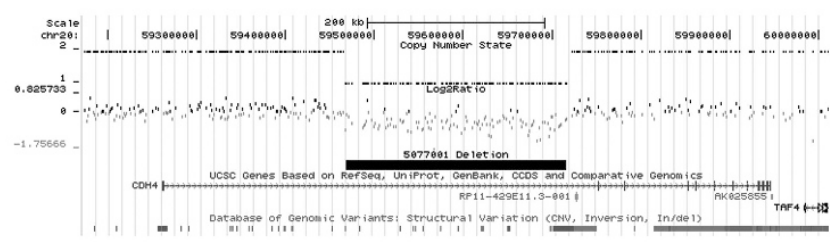

chrXp11.3

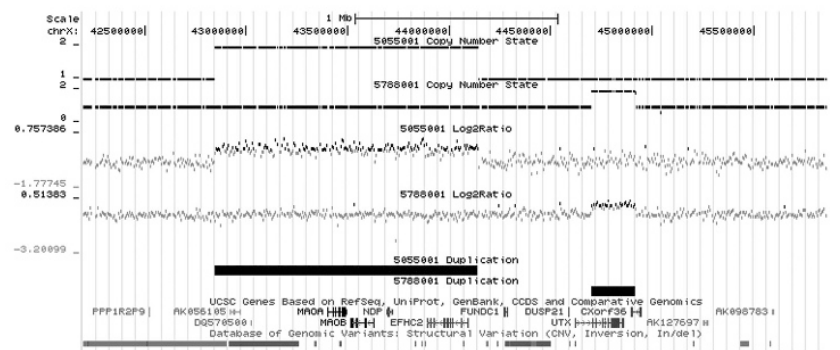

Figure 3 CNVs identified in talipes equinovarus patients and the genes located within them. Log2 ratios and copy number state are shown for rare CNVs identified in isolated talipes equinovarus probands. UCSC candidate genes (hg18 build of the UCSC genome browser) are indicated. Note that the two patients were found to have identical chr17q23.1q23.2 CNVs, and non-overlapping nearby chrXp11.3 duplications were detected in two separate patients. The chr6q14.2q14.3 duplications that are nearly contiguous were found in a single patient. More details about these CNVs are shown in Table 3.

in large cohorts and combined with segregation analysis in disorders that do not significantly alter reproductive fitness.

Several of the CNVs segregating with talipes equinovarus that we identified in this study contain transcription factors or transcriptional regulators of hindlimb development, including PITX1, TBX4, HOXC13, RIPPLY2, CHD (chromodomain protein)1, and UTX (Figure 4). As a class, transcription factors are more likely than other genes to cause disease in a haploinsufficient state, and are therefore more likely to be causative when present within a $\mathrm{CNV}^{35,49}$ Specifically, many of the candidate genes within the CNVs that segregate with isolated talipes equinovarus have a low haploinsufficiency index (Table 1), indicating a high predicted probability of being haploinsufficient. ${ }^{35}$ Furthermore, many human disorders caused by transcription factor haploinsufficiency also result in incompletely penetrant phenotypes, ${ }^{50}$ consistent with previously described complex segregation of talipes equinovarus in families. ${ }^{10}$

Interestingly, several genes located within the talipes equinovarus CNVs are specifically expressed in the hindlimb compared with the forelimb or known to be involved in early embryonic patterning. PITX1 and TBX4 are transcription factors that are essential for normal lower limb development ${ }^{17,28,29,51}$ and CNVs involving each are associated with talipes equinovarus. ${ }^{18,22,52}$ Although we identified recurrent duplications of chromosome $17 \mathrm{q} 23$ involving TBX4 in this report, reciprocal deletions have also been associated with talipes equinovarus. ${ }^{22}$ Vertebrate HOX genes are important for embryonic patterning ${ }^{53,54}$ and limb bud formation, ${ }^{55-61}$ and mutations in HOXD and HOXA genes have previously been shown to cause non-talipes equinovarus limb malformations. ${ }^{62,63}$ Here, we identified a small 
Table 4 Clinically relevant recurrent genomic variants identified in talipes equinovarus probands

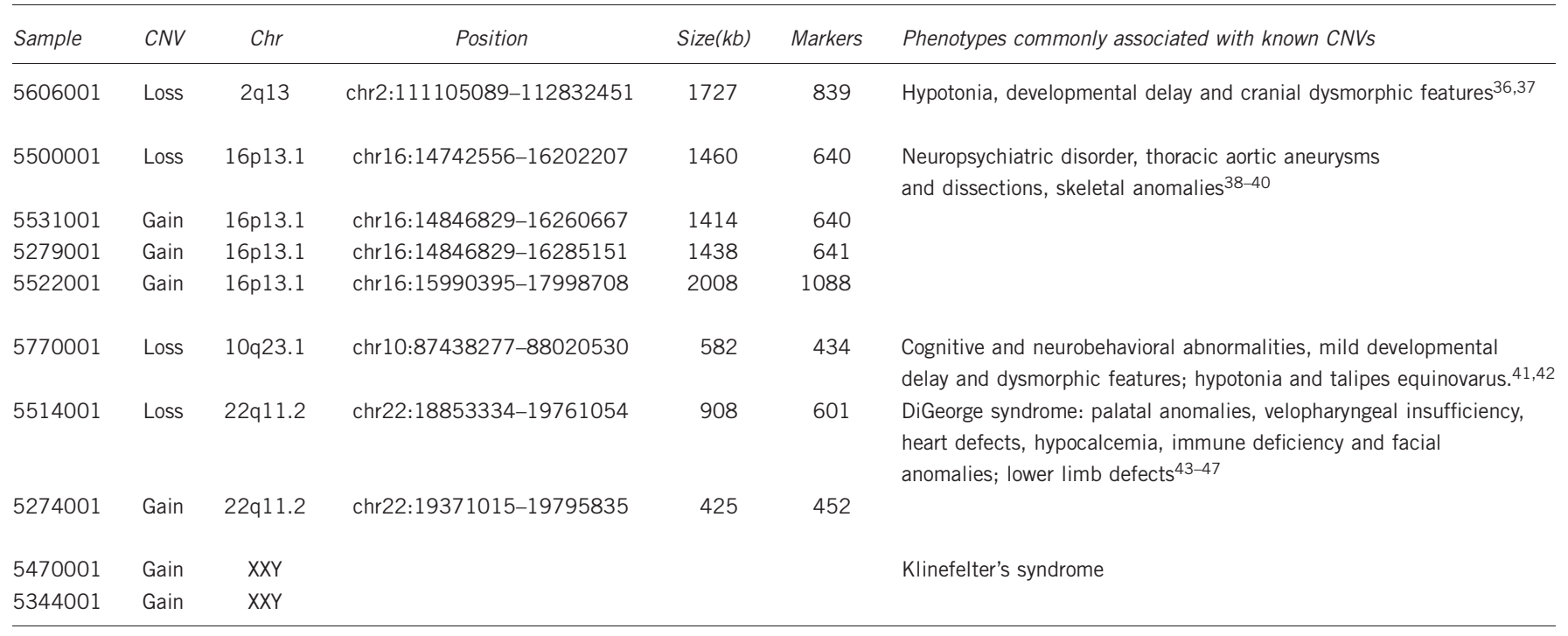

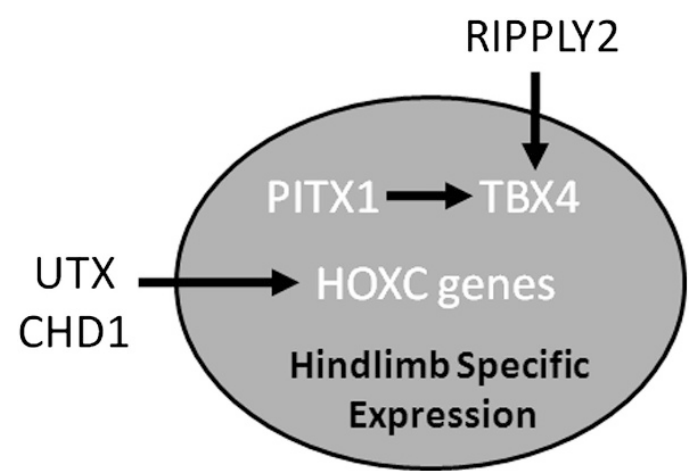

Figure 4 Hindlimb transcriptional regulatory pathway genes suggested to be important in talipes equinovarus pathogenesis. Three hindlimb specific genes (PITX1, TBX4 and HOXC) and their transcriptional regulators (UTX, CHD1 and RIPPLY2) are contained within CNVs that segregate with talipes equinovarus, suggesting an important role for these genetic pathways in talipes equinovarus etiology.

chromosome 12q13.13 deletion involving only the $5^{\prime}$ upstream regulatory region of the HOXC cluster and the first exon of HOXC13 that segregates with talipes equinovarus over three generations. Similar to PITX1 and TBX4, the HOXC $5^{\prime}$ genes are differentially expressed in the hindlimb compared with the forelimb, ${ }^{64}$ making these genes compelling candidates for talipes equinovarus. However, talipes equinovarus was not described in HOXC13 knockout mice, whose limb defects appeared to be restricted to nail hypoplasia. ${ }^{65}$ This suggests the intriguing possibility that the chromosome 12q13.13 talipes equinovarus phenotype may specifically result from deletion of regulatory regions that regulate the expression of other HOXC genes or noncoding RNAs (ie, HOTAIR) during lower limb development.

We also identified CNVs in talipes equinovarus patients that involve CHD1 and UTX, two genes that were previously shown to have a functional role in regulating HOXC gene transcription. ${ }^{66,67}$ A de novo chromosome 5q21.1 deletion that disrupts the CHD1 was found in a female with isolated talipes equinovarus and a duplication of the ubiquitously transcribed tetratricopeptide repeat gene on $\mathrm{X}$ chromosome (UTX) was found to segregate with familial talipes equinovarus. $\mathrm{CHD} 1$ recognizes $\mathrm{H} 3 \mathrm{~K} 4 \mathrm{me}$ and promotes transcriptional elongation of hypomethylated HOX genes in mouse hindlimb fibroblasts. ${ }^{66}$ UTX is enriched around the transcription start sites of HOX genes in primary human fibroblasts and has been shown to regulate $\mathrm{H} 3 \mathrm{~K} 27$ methylation at $\mathrm{HOX}$ gene promoters. ${ }^{67}$ Morpholino inhibition of zebrafish UTX results in misregulation of HOX genes and developmental defects in posterior somitogenesis. ${ }^{67}$ Our identification of CNVs affecting CHD1 and UTX regulators of $H O X$ genes and the $5^{\prime}$ regulatory region of the HOXC gene cluster suggests that impaired regulation of HOX genes may be an important mechanism of talipes equinovarus development. A role for altered $H O X$ gene expression in talipes equinovarus susceptibility is consistent with candidate gene studies that have shown an association of talipes equinovarus with common single nucleotide polymorphisms near $H O X$ genes, ${ }^{14}$ though specific polymorphisms near the HOXC cluster have not yet been evaluated.

RIPPLY2 is an intriguing candidate for talipes equinovarus as it is essential for segmentation of the axial skeleton during mouse embryogenesis and establishment of rostrocaudal polarity during somite segmentation. ${ }^{68,69}$ We identified a chromosome $6 \mathrm{q} 14.2$ microduplication involving RIPPLY2 that incompletely segregates with talipes equinovarus over three generations. Furthermore, the RIPPLY family of proteins have previously been shown to regulate T-box transcription factors during embryogenesis, ${ }^{70}$ suggesting a possible link to the PITX1-TBX4 pathway during limb development.

Four novel CNVs were verified in talipes equinovarus probands that do not segregate with disease. Although these novel CNVs are neither necessary nor sufficient for the talipes equinovarus phenotype, these CNVs should not be excluded from future study as they may be low-penetrant risk factors or modifiers of the talipes equinovarus phenotype.

Currently, prenatal karyotyping is variably recommended for isolated talipes equinovarus based on a $0-5.9 \%$ frequency of karyotype abnormalities. ${ }^{71,72}$ Interpretation of CNVs identified for clinical purposes will be aided by the additional knowledge of variants that are associated with isolated birth defects, as we have begun to uncover in the current study. Clinical relevance is also supported by 
our observation that the chromosome $17 \mathrm{q} 23 \mathrm{CNV}$ containing TBX4 is associated with severe, treatment-resistant talipes equinovarus. ${ }^{22}$ Although our data set represents one of the largest CNV studies of an isolated birth defect, thousands of additional patients with isolated birth defects need to be studied to avoid the current ascertainment bias present in both the literature and variant databases that stems from data based predominantly on children with neurocognitive disorders or multiple congenital anomalies.

Potentially important recurrent CNVs or aneuploidy were identified in $2.2 \%$ of our isolated talipes equinovarus probands. Interestingly, XXY (Klinefelter's syndrome) was identified in 2 out of 281 males in our study, compared with a recently reported frequency of nearly 1 in 500 males. $^{73}$ Although these two are not statistically significant by themselves, three additional males with known XXY karyotype are present in our Washington University Talipes Equinovarus Database but were excluded from this study, resulting in an overall $\sim 1 \%$ incidence of $\mathrm{XXY}$ in males with talipes equinovarus (5/581). The clinical significance of the chromosome 16 p13.1 duplication is unclear, as the frequency of duplication in our talipes equinovarus population is nearly as high as that reported in patients with thoracic aortic disease. If this $\mathrm{CNV}$ is truly overrepresented in talipes equinovarus, then it will be interesting to determine the mechanism by which this $\mathrm{CNV}$ is associated with such diverse disorders.

The results of our study suggest that while there is not an overall increase in CNVs in talipes equinovarus patients, clinically important CNVs may alter the recurrence risk in some families. We anticipate that the data set of genes involved in the CNVs that we identify here will be extremely valuable to future whole-genome sequencing studies as mutations in these genes or nearby enhancers might cause isolated talipes equinovarus in other cases. Finally, our results are beginning to reveal pathways that might be important in the talipes equinovarus pathogenesis. Further understanding of these genetic pathways may lead to improvements in the care of children with limb birth defects.

\section{CONFLICT OF INTEREST}

Dr Gurnett's and Dr Dobbs' work has been funded by The Children's Discovery Institute, and Shriners Hospital for Children. Dr Dobbs' work is also supported by the St Louis Children's Hospital Foundation, The Orthopaedic Research and Education Foundation, The Pediatric Orthopaedic Society of North America. Dr Alvarado's work has been funded by Shriners Hospital for Children and The WM Keck Foundation. The remaining authors declare no conflict of interest.

\section{ACKNOWLEDGEMENTS}

We kindly thank Seth Crosby and Mike Heinz at the Washington University Genome Center for processing the Affymetrix microarrays. The control data set used for the analysis described in this manuscript was obtained from the database of Genotype and Phenotype (dbGaP) (http://www.ncbi.nlm.nih.gov/ gap) through dbGaP accession number phs000017.v3.p1. Data for control samples were provided by John R Kelsoe and John Nurnberger as part of the NIMH Bipolar Genetics Collaborative. Control samples were genotyped through the Genetic Association Information Network (GAIN).

1 Wynne-Davies R: Genetic and environmental factors in the etiology of talipes equinovarus. Clin Orthop Relat Res 1972; 84: 9-13.

2 Brewer C, Holloway S, Zawalnyski P, Schinzel A, FitzPatrick D: A chromosomal deletion map of human malformations. Am J Hum Genet 1998; 63: 1153-1159.

3 Gurnett CA, Boehm S, Connolly A, Reimschisel T, Dobbs MB: Impact of congenital talipes equinovarus etiology on treatment outcomes. Dev Med Child Neurol 2008; 50. 498-502.
4 Bill PL, Versfeld GA: Congenital clubfoot: an electromyographic study. J Pediatr Orthop 1982; 2: 139-142.

5 Feldbrin Z, Gilai AN, Ezra E, Khermosh O, Kramer U, Wientroub S: Muscle imbalance in the aetiology of idiopathic club foot. An electromyographic study. J Bone Joint Surg $\mathrm{Br}$ 1995; 77: 596-601.

6 Herceg MB, Weiner DS, Agamanolis DP, Hawk D: Histologic and histochemical analysis of muscle specimens in idiopathic talipes equinovarus. J Pediatr Orthop 2006; 26: 91-93.

7 Isaacs H, Handelsman JE, Badenhorst M, Pickering A: The muscles in club foot-a histological histochemical and electron microscopic study. J Bone Joint Surg Br 1977; 59-B: 465-472.

8 Wynne-Davies R: Family studies and the cause of congenital club foot. Talipes Equinovarus, Talipes Calcaneo-Valgus and Metatarsus Varus. J Bone Joint Surg $\mathrm{Br}$ 1964; 46: 445-463.

9 Lochmiller C, Johnston D, Scott A, Risman M, Hecht JT: Genetic epidemiology study of idiopathic talipes equinovarus. Am J Med Genet 1998; 79: 90-96.

10 Chapman C, Stott NS, Port RV, Nicol RO: Genetics of club foot in Maori and Pacific people. J Med Genet 2000; 37: 680-683.

11 de Andrade M, Barnholtz JS, Amos Cl et al: Segregation analysis of idiopathic talipes equinovarus in a Texan population. Am J Med Genet 1998; 79: 97-102.

12 Rebbeck TR, Dietz FR, Murray JC, Buetow KH: A single-gene explanation for the probability of having idiopathic talipes equinovarus. Am J Hum Genet 1993; 53: 1051-1063.

13 Kruse LM, Dobbs MB, Gurnett CA: Polygenic threshold model with sex dimorphism in talipes equinovarus inheritance: the Carter effect. J Bone Joint Surg Am 2008; 90: 2688-2694.

14 Ester AR, Weymouth KS, Burt A et al: Altered transmission of HOX and apoptotic SNPS identify a potential common pathway for talipes equinovarus. Am J Med Genet $A$ 2009; 149A: 2745-2752.

15 Ester AR, Tyerman G, Wise CA, Blanton SH, Hecht JT: Apoptotic gene analysis in idiopathic talipes equinovarus (talipes equinovarus). Clin Orthop Relat Res 2007; 462: 32-37.

16 Gurnett CA, Alaee F, Kruse LM et al: Asymmetric lower-limb malformations in individuals with homeobox PITX1 gene mutation. Am J Hum Genet 2008; 83: 616-622.

17 Szeto DP, Rodriguez-Esteban C, Ryan AK et al: Role of the Bicoid-related homeodomain factor Pitx1 in specifying hindlimb morphogenesis and pituitary development. Genes Dev 1999; 13: 484-494.

18 Alvarado DM, McCall K, Aferol H et al: Pitx1 haploinsufficiency causes Talipes equinovarus in Humans and a Talipes equinovarus-like phenotype in Mice. Hum $\mathrm{Mol}$ Genet 2011.

19 Cook Jr. EH, Scherer SW: Copy-number variations associated with neuropsychiatric conditions. Nature 2008; 455: 919-923.

20 Morrow EM: Genomic copy number variation in disorders of cognitive development. J Am Acad Child Adolesc Psychiatry 2010; 49: 1091-1104.

21 Stankiewicz P, Lupski JR: Structural variation in the human genome and its role in disease. Annu Rev Med 2010; 61: 437-455.

22 Alvarado DM, Aferol $\mathrm{H}$, McCall $\mathrm{K}$ et al: Familial isolated talipes equinovarus is associated with recurrent chromosome 17q23.1q23.2 microduplications containing TBX4. Am J Hum Genet 2010; 87: 154-160.

23 Greenway SC, Pereira AC, Lin JC et al: De novo copy number variants identify new genes and loci in isolated sporadic tetralogy of Fallot. Nat Genet 2009; 41: 931-935.

24 Mefford HC, Shafer N, Antonacci F et al: Copy number variation analysis in singlesuture craniosynostosis: multiple rare variants including RUNX2 duplication in two cousins with metopic craniosynostosis. Am J Med Genet A 2010; 152A: 2203-2210.

25 Wat MJ, Veenma D, Hogue J et al: Genomic alterations that contribute to the development of isolated and non-isolated congenital diaphragmatic hernia. J Med Genet 2011; 48: 299-307.

26 Logan M, Tabin CJ: Role of Pitx1 upstream of Tbx4 in specification of hindlimb identity. Science 1999; 283: 1736-1739.

27 Menke DB, Guenther C, Kingsley DM: Dual hindlimb control elements in the Tbx4 gene and region-specific control of bone size in vertebrate limbs. Development 2008; 135: 2543-2553.

28 Hasson P, DeLaurier A, Bennett M et al: Tbx4 and tbx5 acting in connective tissue are required for limb muscle and tendon patterning. Dev Cell 2010; 18: 148-156.

29 Naiche LA, Papaioannou VE: Tbx4 is not required for hindlimb identity or post-bud hindlimb outgrowth. Development 2007; 134: 93-103.

30 Rodriguez-Esteban C, Tsukui T, Yonei S, Magallon J, Tamura K, Izpisua Belmonte JC: The T-box genes Tbx4 and Tbx5 regulate limb outgrowth and identity. Nature 1999; 398: 814-818.

31 Takeuchi JK, Koshiba-Takeuchi K, Matsumoto $\mathrm{K}$ et al: Tbx5 and Tbx4 genes determine the wing/leg identity of limb buds. Nature 1999; 398: 810-814.

32 Dick DM, Foroud T, Flury L et al: Genomewide linkage analyses of bipolar disorder: a new sample of 250 pedigrees from the National Institute of Mental Health Genetics Initiative. Am J Hum Genet 2003; 73: 107-114.

33 McInnis MG, Dick DM, Willour VL et al: Genome-wide scan and conditional analysis in bipolar disorder: evidence for genomic interaction in the National Institute of Mental Health genetics initiative bipolar pedigrees. Biol Psychiatry 2003; 54: 1265-1273.

34 Illumina: Gene Expression Microarray Data Quality Control 2010.

35 Huang N, Lee I, Marcotte EM, Hurles ME: Characterising and predicting haploinsufficiency in the human genome. PLoS Genet 2010; 6: e1001154.

36 Rudd MK, Keene J, Bunke B et al: Segmental duplications mediate novel, clinically relevant chromosome rearrangements. Hum Mol Genet 2009; 18: 2957-2962. 
$37 \mathrm{Yu} \mathrm{HY}$, Hawash K, Picker J et al: A recurrent $1.71 \mathrm{Mb}$ genomic imbalance at $2 \mathrm{q} 13$ increases the risk of developmental delay and dysmorphism. Clin Genet 2011.

38 Ingason A, Rujescu D, Cichon S et al: Copy number variations of chromosome $16 p 13.1$ region associated with schizophrenia. Mol Psychiatry 2011; 16: 17-25.

39 Kuang SQ, Guo DC, Prakash SK et al: Recurrent chromosome 16p13.1 duplications are a risk factor for aortic dissections. PLoS Genet 2011; 7: e1002118.

40 Nagamani SC, Erez A, Bader $\mathrm{P}$ et al: Phenotypic manifestations of copy number variation in chromosome 16p13.11. Eur J Hum Genet 2011; 19: 280-286.

41 Alliman S, Coppinger J, Marcadier J et al: Clinical and molecular characterization of individuals with recurrent genomic disorder at 10q22.3q23.2. Clin Genet 2010; 78: $162-168$.

42 van Bon BW, Balciuniene J, Fruhman G et al: The phenotype of recurrent 10q22q23 deletions and duplications. Eur J Hum Genet 2011; 19: 400-408.

43 Driscoll DA, Budarf ML, Emanuel BS: A genetic etiology for DiGeorge syndrome: consistent deletions and microdeletions of 22q11. Am J Hum Genet 1992; 50: 924-933.

44 Scambler PJ, Carey AH, Wyse RK et al: Microdeletions within 22q11 associated with sporadic and familial DiGeorge syndrome. Genomics 1991; 10: 201-206.

45 Dundar M, Kiraz A, Tasdemir S et al: Unbalanced 3;22 translocation with 22q11 and $3 p$ deletion syndrome. Am J Med Genet A 2010; 152A: 2791-2795.

46 Elder DA, Kaiser-Rogers K, Aylsworth AS, Calikoglu AS: Type I diabetes mellitus in a patient with chromosome 22q11.2 deletion syndrome. Am J Med Genet 2001; 101: 17-19.

47 Ming JE, McDonald-McGinn DM, Megerian TE et al: Skeletal anomalies and deformities in patients with deletions of 22q11. Am J Med Genet 1997; 72: 210-215.

48 Erdogan F, Belloso JM, Gabau E et al: Fine mapping of a de novo interstitial 10q22q23 duplication in a patient with congenital heart disease and microcephaly. Eur Med Genet 2008; 51: 81-86.

49 Dang VT, Kassahn KS, Marcos AE, Ragan MA: Identification of human haploinsufficient genes and their genomic proximity to segmental duplications. Eur J Hum Genet 2008; 16: 1350-1357.

50 Veitia RA, Birchler JA: Dominance and gene dosage balance in health and disease: why levels matter!. J Pathol 2010; 220: 174-185.

51 Lanctot C, Moreau A, Chamberland M, Tremblay ML, Drouin J: Hindlimb patterning and mandible development require the Ptx1 gene. Development 1999; 126: 1805-1810.

52 Rosenfeld JA, Drautz JM, Clericuzio CL et al: Deletions and duplications of developmental pathway genes in $5 q 31$ contribute to abnormal phenotypes. Am J Med Genet A 2011; 155: 1906-1916.

53 Burke AC, Nelson CE, Morgan BA, Tabin C: Hox genes and the evolution of vertebrate axial morphology. Development 1995; 121: 333-346.

54 Kessel M, Gruss P: Murine developmental control genes. Science 1990; 249: 374-379.
55 Davis AP, Capecchi MR: Axial homeosis and appendicular skeleton defects in mice with a targeted disruption of hoxd-11. Development 1994; 120: 2187-2198.

56 Davis AP, Witte DP, Hsieh-Li HM, Potter SS, Capecchi MR: Absence of radius and ulna in mice lacking hoxa-11 and hoxd-11. Nature 1995; 375: 791-795.

57 Dolle P, Dierich A, LeMeur M et al: Disruption of the Hoxd-13 gene induces localized heterochrony leading to mice with neotenic limbs. Cell 1993; 75: 431-441.

58 Favier B, Le Meur M, Chambon P, Dolle P: Axial skeleton homeosis and forelimb malformations in Hoxd-11 mutant mice. Proc Natl Acad Sci USA 1995; 92: 310-314.

59 Morgan BA, Izpisua-Belmonte JC, Duboule D, Tabin CJ: Targeted misexpression of Hox-4.6 in the avian limb bud causes apparent homeotic transformations. Nature 1992; 358: 236-239.

60 Morgan BA, Tabin C: Hox genes and growth: early and late roles in limb bud morphogenesis. Dev Supp/ 1994; 181-186.

61 Hostikka SL, Gong J, Carpenter EM: Axial and appendicular skeletal transformations, ligament alterations, and motor neuron loss in Hoxc10 mutants. Int J Biol Sci 2009; 5: 397-410.

62 Mortlock DP, Innis JW: Mutation of HOXA13 in hand-foot-genital syndrome. Nat Genet 1997; 15: 179-180.

63 Muragaki Y, Mundlos S, Upton J, Olsen BR: Altered growth and branching patterns in synpolydactyly caused by mutations in HOXD13. Science 1996; 272: 548-551.

64 Nelson CE, Morgan BA, Burke AC et al: Analysis of Hox gene expression in the chick limb bud. Development 1996; 122: 1449-1466.

65 Godwin AR, Capecchi MR: Hoxc13 mutant mice lack external hair. Genes Dev 1998; 12: $11-20$

66 Tao Y, Xi S, Briones V, Muegge K: Lsh mediated RNA polymerase II stalling at HoxC6 and HoxC8 involves DNA methylation. PLoS One 2010; 5: e9163.

67 Lan F, Bayliss PE, Rinn JL et al: A histone H3 lysine 27 demethylase regulates animal posterior development. Nature 2007; 449: 689-694.

68 Chan T, Kondow A, Hosoya A et al: Ripply2 is essential for precise somite formation during mouse early development. FEBS Lett 2007; 581: 2691-2696.

69 Takahashi J, Ohbayashi A, Oginuma M et al: Analysis of Ripply1/2-deficient mouse embryos reveals a mechanism underlying the rostro-caudal patterning within a somite. Dev Biol 2010; 342: 134-145.

70 Kawamura A, Koshida S, Takada S: Activator-to-repressor conversion of T-box transcription factors by the Ripply family of Groucho/TLE-associated mediators. Mol Cell Biol 2008; 28: 3236-3244.

71 Malone FD, Marino T, Bianchi DW, Johnston K, D'Alton ME: Isolated talipes equinovarus diagnosed prenatally: is karyotyping indicated? Obstet Gynecol 2000; 95: 437-440.

72 Shipp TD, Benacerraf BR: The significance of prenatally identified isolated talipes equinovarus: is amniocentesis indicated? Am J Obstet Gynecol 1998; 178: 600-602.

73 Morris JK, Alberman E, Scott C, Jacobs P: Is the prevalence of Klinefelter syndrome increasing? Eur J Hum Genet 2008; 16: 163-170.

Supplementary Information accompanies the paper on European Journal of Human Genetics website (http://www.nature.com/ejhg) 